\title{
CARACTERIZAÇÃO FÍSICO-QUÍMICA DE FARINHAS DE MANDIOCA DE DSIFERENTES LOCALIDADES DO BRASIL
}

\author{
Phisico-chemical characteristics of cassava flours from different regions of Brazil
}

\author{
Larissa Tavares Dias ${ }^{1}$, Magali Leonel ${ }^{2}$
}

\begin{abstract}
RESUMO
A farinha de mandioca (Manihot esculenta Crantz) é produzida em diferentes regiões do Brasil e faz parte do hábito alimentar do brasileiro. Caracteriza-se num alimento de alto valor energético, possui teor elevado de amido, contém fibras e alguns minerais como potássio, cálcio, fósforo, sódio e ferro. Entre os diferentes estados, os do Norte e Nordeste consomem quantidades de farinha de mandioca bem maiores que os demais. Frente à importância econômica e nutricional deste produto, com o presente trabalho, objetivou-se caracterizar farinhas de mandioca de diferentes estados do País, esperando com isso fornecer informações referentes à composição e às características físico-químicas do produto, tanto para as indústrias produtoras quanto aos consumidores. Os resultados obtidos mostraram que, quanto à composição centesimal, as farinhas analisadas diferem entre si e entre as regiões produtoras, inclusive para classificações de mesmo grupo e subgrupo. Para proteínas e acidez, as farinhas não estão de acordo com os limites da legislação. As farinhas apresentam teores baixos a moderados de fibras, contudo, devido ao seu amplo consumo, contribui como importante fornecedor de fibras na alimentação. A classificação de algumas farinhas quanto à cor não está de acordo com as análises de seus componentes de cromaticidade.
\end{abstract}

Termos de indexação: Farinha, mandioca, composição, fibras, classificação, Manihot esculenta.

\begin{abstract}
Cassava flours (Manihot esculenta Crantz) are produced in all Brazilian states and it is part of Brazilian alimentary habit. Cassava flour is characterized as high-energy food, with high level of starch, and it contains fibers and some minerals as potassium, calcium, match, sodium and iron. In the North and Northeast regions the consumption of this flour is larger than the others. Due the economical and nutritional importance of the cassava flour the present work had as objective to characterize cassava flours from different Brazilian states aiming to supply industries and consumer with important nutritional and technological characteristics information. The results showed that cassava flours differ to each other and among the producing states to centesimal composition besides to belong to the same classification group. The analyzed flours are not in agreement with the legislation limits for proteins and acidity. For fibers, the cassava flours showed low to moderate levels, but due the high consumption could be considerate as important source of fiber. The flours color analysis showed that commercial classifications of some cassava flours differ of the analytical results obtained.
\end{abstract}

Index terms: Flour, cassava, constituents, fiber, classification, Manihot esculenta.

(Recebido para publicação em 22 de junho de 2005 e aprovado em 27 de dezembro de 2005)

\section{INTRODUÇÃO}

A raiz de mandioca (Manihot esculenta Crantz) é cultivada nas mais diversas regiões do Brasil e sua produção tem sido dirigida tanto para consumo direto como para indústria de transformação. De acordo com Ferreira Neto et al. (2003), devido a raiz de mandioca recém-colhida ser um produto altamente perecível (teor de umidade em torno de 60\%), sua utilização por tempo prolongado se dá através de produtos desidratados. A redução do teor de umidade dessas raízes dificulta o desenvolvimento microbiano, evitando a conseqüente deterioração do produto. Estes produtos desidratados são, principalmente, os diversos tipos de farinhas de mandioca, o amido utilizado tanto no preparo caseiro como industrial e a raspa utilizada para ração animal (VILELA, 1987, citado por FERREIRA NETO et al., 2003).

A farinha constitui um dos principais produtos da mandioca, e seu uso é muito difundido em todo o País, fazendo parte da refeição diária da maioria dos brasileiros, especialmente das regiões Norte e Nordeste. Caracterizase num alimento de alto valor energético, rico em amido, contém fibras e alguns minerais como potássio, cálcio, fósforo, sódio e ferro. Sgarbieri (1987) relata que na região Norte, a farinha é extremamente importante para o aporte de energia (20 a 50\% do total) e de ferro (30 a 40\% do total, porém de baixa biodisponibilidade) ingerido pelas populações rurais e urbanas de baixa renda, sendo mais consumida sob a forma de beijus, mingaus e farofas. Já no Nordeste, a farinha é bastante consumida na forma de pirão,

Aluna de Nutrição, bolsista PIBIC/CNPq - Instituto de Biociências/UNESP - Botucatu, SP.

${ }^{2}$ Pesquisadora, Centro de Raízes e Amidos Tropicais (CERAT)/UNESP - Cx. P. 237 - 18603-970 - Botucatu, SP - mleonel@fca.unesp.br 
ou acompanhando o feijão, a carne seca, o café e a rapadura, além de fazer parte de pratos típicos da região. A farinha de tapioca também é muito presente no hábito alimentar dessas populações. Na região amazônica, esta farinha é consumida na forma de mingaus, roscas, bolos, pudins, sorvetes, assim como acompanhando o extrato de frutas de palmeiras denominadas açaí (CEREDA \& VILPOUX, 2003).

De acordo com a Legislação Brasileira, farinha é o produto obtido da moagem da parte comestível de vegetais, podendo sofrer processos tecnológicos adequados, devendo o produto ser denominado de farinha seguido do nome do vegetal de origem. A farinha de mandioca é o produto obtido pela ligeira torração da raladura das raízes de mandioca previamente descascadas, lavadas e isentas do radical cianeto. $\mathrm{O}$ produto submetido à nova torração é denominado "farinha de mandioca torrada". Já a farinha de tapioca pode ser definida como um produto obtido sob a forma granulada a partir da fécula de mandioca e submetido a processo tecnológico adequado. As fases de fabricação da farinha de tapioca são o esfarelamento, encaroçamento, escaldamento, expansão (chamada localmente de espocagem), classificação e embalagem (BRASIL, 1978).

A escala de operação das indústrias de processamento de farinha vai desde as pequenas unidades artesanais de processamento (casas de farinha comunitárias ou privadas, que produzem entre 6 a 10 sacas de farinha por dia), existentes em todo o Brasil, principalmente na região Norte/Nordeste, até as unidades de grande porte que processam, em média, 300 sacas de farinha por dia, passando pelas unidades de médio porte, que possuem capacidade instalada para processar 100 sacas por dia. É difícil precisar o número dessas unidades no Brasil, mas apenas no Estado do Paraná estima-se que existam mais de 250 farinheiras concentradas, na região de Paranavaí.

Apesar da farinha constituir a forma mais ampla de aproveitamento industrial da mandioca, ela não é um produto muito valorizado, sobretudo pela falta de uniformidade. Essa heterogeneidade é devida principalmente à fabricação por pequenos produtores para seu uso, cada um deles seguindo processo próprio, além de existirem muitos tipos de farinha nas diferentes regiões do Brasil. A granulometria constitui um aspecto de qualidade importante na padronização deste produto. Muitas vezes, tais classificações são particulares a cada fabricante, com denominações de grossa, média e fina que não obedecem a padrões ou técnicas descritas na legislação.
As diferenças existentes entre as farinhas podem ser devidas principalmente ao processamento, como temperatura e carga no forno de secagem, intensidade da prensagem e fermentação da mandioca antes da secagem. Neste trabalho, objetivou-se caracterizar farinhas de mandioca de diferentes Estados do Brasil, esperando com isso fornecer informações sobre a composição nutricional e características do produto (granulometria, colorimetria, $\mathrm{pH}$ e acidez), às indústrias produtoras e aos consumidores.

\section{MATERIAL E MÉTODOS}

Foram analisadas farinhas comerciais de mandioca com classificações e procedências diversas (Tabela 1). As farinhas de mandioca foram analisadas quanto à composição centesimal, pH, acidez, granulometria e colorimetria.

\section{Caracterização das farinhas de mandioca}

$\mathrm{O}$ teor de umidade das farinhas foi determinado usando-se estufa com circulação de ar a $105^{\circ} \mathrm{C}$ por 8 horas. Para a determinação do teor de cinzas utilizou-se mufla a $550^{\circ} \mathrm{C}$ por 2 horas. A determinação do teor de fibra bruta foi feita através de digestão do material em solução de $\mathrm{H}_{2} \mathrm{SO}_{4}$ a $1,25 \%$ p/v por 30 minutos, seguida de $\mathrm{NaOH} 1,25 \%$ p/v por mais 30 minutos. A determinação do teor de matéria graxa foi realizada em extrator Soxleth completo, utilizando-se éter de petróleo para a extração, por 8horas. Para a avaliação do teor de proteína das amostras utilizou-se destilador micro-Kjeldahl e bloco digestor, avaliando-se a porcentagem de nitrogênio na amostra. A conversão para proteína foi feita por $\mathrm{N}$ x 6,25 (AOAC, 1980).

Na determinação dos açúcares totais, pesou-se $0,5 \mathrm{~g}$ de amostra em um erlenmeyer de $250 \mathrm{~mL}$ acrescentando-se $30 \mathrm{~mL}$ de etanol absoluto P.A., em seguida adicionou-se 30 $\mathrm{mL}$ de água destilada, levando-se a banho com aquecimento entre $60-65^{\circ} \mathrm{C}$ por 60 minutos. Depois se acrescentou $1 \mathrm{~mL}$ de $\mathrm{HCl} \mathrm{P.A.} \mathrm{concentrado} \mathrm{e} \mathrm{agitou-se,} \mathrm{retornando} \mathrm{ao} \mathrm{banho}$ por mais uma hora na mesma temperatura. Após este tempo, resfriou-se a amostra e esta foi transferida para balão volumétrico de $250 \mathrm{~mL}$, efetuando-se a neutralização com solução saturada de carbonato de sódio. Adicionou-se 1 a $2 \mathrm{~mL}$ de solução de hidróxido de bário a $0,3 \mathrm{~N}$ e 1 a $2 \mathrm{~mL}$ de solução de sulfato de zinco a 5\% e completou-se o volume do balão com água destilada. Após agitação, retirou-se uma amostra do material e centrifugou-se, sendo então determinado o teor de açúcares totais (NELSON, 1944; SOMOGY, 1945). 
TABELA 1 - Classificação e procedência das farinhas comerciais de mandioca.

\begin{tabular}{cccccc}
\hline $\begin{array}{c}\text { Farinhas de } \\
\text { mandioca }\end{array}$ & Grupo & Subgrupo & Classe & Tipo & \multirow{2}{*}{ Procedência } \\
\hline F1 & D'água & Fina & Branca & 1 & Maranhão \\
F2 & D'água & Fina & Amarela & 1 & Maranhão \\
F3 & Seca & Grossa & Branca & $1 /$ Crua & São Paulo \\
F4 & Seca & Fina & Branca & 2 & São Paulo \\
F5 & Seca & Fina & Amarela & $1 /$ Torrada & São Paulo \\
F6 & Seca & Bijusada & Amarela & único & São Paulo \\
F7 & Seca & Fina & Branca & 1 & Mato Grosso \\
F8 & Seca & Média & Amarela & 1 & Acre \\
F9 & Seca & Fina & Amarela & 1 & Minas Gerais \\
F10 & D'água & Média & Creme & 1 & Pará \\
F11 & Seca & Grossa & Branca & 1 & Pará \\
F12 & Seca & Fina & Amarela & 1 & Pará \\
F13 & Seca & Grossa & Amarela & 1 & Pará \\
F14 & Tapioca & Granulado & - & 1 & Pará \\
F15 & Seca & Fina & Branca & 1 & Sergipe \\
\hline
\end{tabular}

O teor de amido foi calculado pela diferença dos outros componentes da amostra (umidade, cinzas, proteínas, matéria graxa, fibras e açúcar solúvel total), segundo normas do Instituto Adolfo Lutz (1976).

A determinação do $\mathrm{pH}$ e da acidez titulável das farinhas de mandioca foi feita segundo metodologia proposta pela AOAC (1980).

\section{Análise granulométrica}

Para a determinação do tamanho das partículas das farinhas foi utilizado um equipamento vibratório (Granutest) composto por 14 peneiras, cujas aberturas variaram de 0,045 $\mathrm{mm}$ a $5,6 \mathrm{~mm}$, onde se colocou $100 \mathrm{~g}$ de farinha em agitação por 15 minutos na velocidade máxima, anotando-se a quantidade de amostra retida em cada peneira (CEREDA \& CATÂNEO, 1986).

\section{Colorimetria}

A cor das farinhas de mandioca foi avaliada em colorímetro Minolta CR-200. Os resultados foram expressos em valores L*, a* e b* (BIBLE \& SINGHA, 1993, citados por BORBA, 2005), em que os valores de $\mathrm{L}^{*}$ (luminosidade ou brilho) variam do preto (0) ao branco (100), os valores do croma $a^{*}$ variam do verde $(-60)$ ao vermelho (+60) e os valores do croma $b^{*}$ variam do azul ao amarelo, ou seja, de -60 a +60 , respectivamente.

\section{Análise dos dados}

Os resultados obtidos, referentes à composição das diferentes farinhas de mandioca, foram submetidos à análise estatística, sendo realizada a análise de variância pelo teste F e as comparações das médias pelo teste de Tukey no nível de 5\% de probabilidade (CAMPOS, 1984).

\section{RESULTADOS E DISCUSSÃO}

\section{Caracterização das farinhas}

Os resultados obtidos referentes à caracterização físico-química das farinhas analisadas encontram-se na Tabela 2. A análise do teor de umidade das farinhas mostrou que todas as amostras estão de acordo com o limite estabelecido pela Legislação Brasileira (máximo de 14\%) (BRASIL, 1978). Entre as farinhas do grupo seca (F3, F4, F5, F6, F7, F8, F9, F11, F12, F13 e F15), verificou-se que F3 (SP) e F9 (MG) não diferiram estatisticamente, sendo que F5 (SP) apresentou o menor teor de umidade $(3,10 \%)$. A presença de pouca umidade nesta última pode ser explicada pelo processo complementar de torração a que é submetida, no qual grande parte de sua umidade é retirada. Com relação às farinhas do grupo d'água (F1, F2 e F10), foi observado diferença estatística significante entre elas, inclusive entre farinhas produzidas na mesma região, com maior umidade em F2 (MA) e menor em F10 (PA). Essas diferenças podem 
ser devidas à variação existente entre as comunidades locais produtoras de farinha quanto ao tipo de forno, tempo e a temperatura empregada durante a secagem (VILPOUX, 2003).

Com relação ao teor de cinzas, pode-se observar que todos os valores encontraram-se dentro do limite fixado pela legislação (teor máximo de 2,0\%) (BRASIL, 1978). Valores maiores de cinzas podem indicar fraudes, como adição de areia ou processamento inadequado, com lavagem e descascamento incompletos. Os maiores teores de cinzas encontraram-se nas farinhas secas F15 e F7 $(1,12$ e $1,11 \%$, respectivamente). Um dos fatores que pode ter interferido nesses valores é a presença de sujidades inorgânicas, como terra e areia, provenientes do local de deposição das raízes descascadas, superestimando o conteúdo de cinzas na farinha. Em relação às farinhas d'água, o maior teor foi encontrado em F1 $(0,97 \%)$, seguidos de F10 $(0,73 \%)$ e F2 $(0,48 \%)$, havendo diferença estatística significante entre elas.

Quanto ao teor de fibras, a Legislação Brasileira não estipula valores, contudo, foi possível verificar diferenças significativas deste componente entre as farinhas analisadas. No grupo das farinhas secas, a farinha bijusada F6 foi a que apresentou o maior teor de fibras $(2,75 \%)$, sendo que os menores valores foram encontrados em F8 $(0,89 \%)$ e F13 $(0,57 \%)$. Não houve diferença estatística entre os teores de fibras das farinhas d'água, que variaram de $1,95 \%(\mathrm{~F} 10)$ a $2,22 \%(\mathrm{~F} 1)$.

Mattos \& Martins (2000), citando a quantidade de fibras em diferentes alimentos, adotaram a seguinte classificação: alimentos com teor muito alto de fibras (mínimo $7 \mathrm{~g}$ fibras/100 g); alto (4,5 a 6,9 g fibras/100 g); moderado (2,4 a 4,4 g fibras/100 g) e baixo (inferior a 2,4 $\mathrm{g}$ fibras/100 g). Considerando tal classificação, as farinhas de mandioca analisadas apresentaram teores de fibras moderados (farinhas F4, F9 e F6) a baixos (todas as demais farinhas).

Cereda \& Vilpoux (2003) relataram o consumo de farinha de mandioca nas principais cidades brasileiras, no ano de 1996 e verificaram que o maior consumo foi na cidade de Belém (33,9 kg/hab./ano), seguida de Salvador (14,39 kg/hab./ano), Recife (9,04 kg/hab./ano) e Fortaleza (7,41kg/hab./ano). Com base nestes valores, supondo-se que um habitante de Belém consuma $94 \mathrm{~g}$ de farinha/dia, com 2,34\% de fibras (teor da farinha F12, por exemplo), a quantidade de fibras consumida seria de 2,17 g/dia. Em Salvador, este valor seria de 0,92 g/hab./dia; em Recife, 0,60 g/hab./dia e em Fortaleza, 0,48 g/hab./dia. Tais valores representam uma estimativa do consumo de fibras, porém, sabe-se que determinadas regiões apresentam um consumo de farinha de mandioca bastante superior.

As farinhas apresentaram um teor de proteínas bastante baixo, o que já é esperado frente à composição da raiz de mandioca, que apresenta em média $82,5 \%$ de amido, $2,7 \%$ de fibras, $0,3 \%$ de matéria graxa, $2,4 \%$ de cinzas, $0,2 \%$ de açúcares redutores e 2,6\% de proteínas (\% em massa seca) (CEREDA et al., 2003). Dentre as farinhas secas analisadas, F4 teve o maior teor protéico $(1,08 \%)$ e F12, o menor $(0,57 \%)$. As farinhas d'água da região do Maranhão não diferiram estatisticamente entre si, porém, a farinha F2 diferiu da farinha F10, produzida no Estado do Pará. Todos os valores encontrados situaram-se abaixo do valor indicado pela legislação (teor mínimo de 1,5\%). Segundo Cereda \& Vilpoux (2003), citando teores de proteínas em amostras de farinha de mandioca coletadas em indústrias dos Estados de SP, PR e SC, estes variaram de 1,12 a 1,75\%, valores acima dos encontrados neste trabalho para todas as farinhas analisadas.

Os teores de matéria graxa não estão estabelecidos na legislação. Os valores encontrados nas farinhas secas variaram de $0,15 \%$ (F11) a 1,39\% (F15). Já entre as farinhas d'água, o maior teor foi encontrado em F2 (0,79\%), seguido de F1 $(0,42 \%)$ e F10 $(0,18 \%)$, diferentes estatisticamente entre si. Cereda \& Vilpoux (2003) citaram teores deste componente em farinhas de mandioca crua e torrada (subgrupos fina e grossa), variando de $0,25 \%$ a $0,31 \%$, e para a beiju de $0,24 \%$, semelhante ao observado na farinha F6 de mesma classificação $(0,24 \%)$. O maior teor observado em F15, assim como maiores teores de outros componentes (proteínas, açúcares totais), podem indicar uso de variedade de mandioca rica em outros componentes não amido ou uma menor prensagem da massa ralada durante o processamento, levando a uma menor perda desses componentes na manipueira (água de prensagem).

O teor de açúcares solúveis totais nas farinhas secas variou de $0,26 \%$ (F8) a 3,35\% (F15). Maiores teores encontraram-se nas farinhas de mesma classificação (seca/ fina/branca) das regiões de SE e SP e não diferiram estatisticamente entre si. No grupo das farinhas d'água, observou-se maior presença de açúcares solúveis em F1 $(2,46 \%)$ e baixos teores em F10 $(0,87 \%)$ e F2 $(0,86 \%)$. Os teores deste componente encontrados por Cereda \& Vilpoux (2003) em amostras de farinhas de mandioca crua/ grossa, torrada/fina e beiju, $(2,45,2,20$ e 2,75\%, respectivamente), apresentaram-se acima dos observados para as farinhas F3, F5 e F6 analisadas no presente trabalho. 

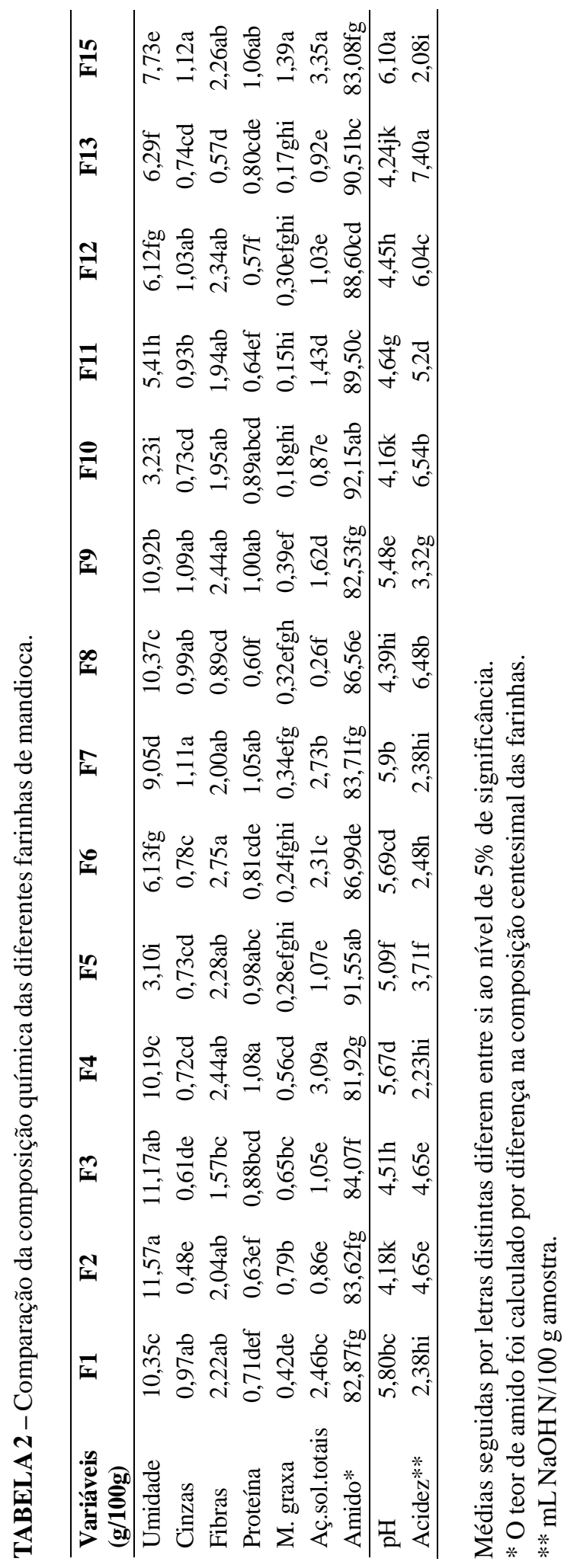

O teor de amido calculado nas farinhas secas variou de $81,92 \%$ (F4) a $91,56 \%$ (F5), acima do valor mínimo preconizado pela legislação (mínimo de 70\%) (BRASIL, 1978). Entre as farinhas d'água, F10 apresentou o maior teor $(92,15 \%)$, diferindo significativamente das farinhas F2 (83,62\%) e F1 (82,87\%). O teor de amido encontrado por Cereda \& Vilpoux (2003) em farinhas de mandioca crua/ grossa e beiju, ( 88,16 e $88,22 \%$, respectivamente), foi superior ao encontrado para as farinhas F3 e F6 (84,07 e 86,99\%, respectivamente) analisadas.

Foi observado que o nível de acidez nas farinhas de mandioca analisadas não esteve de acordo com a Legislação Brasileira (máximo de 2,0 mL NaOH N/100 g), pois este variou de 2,08 (F15) a 7,4 mL NaOH N/100 g (F13). Entre as farinhas d'água, os valores diferiram significativamente, sendo maior em F10 $(6,54 \mathrm{~mL} \mathrm{NaOH}$ N/100 g) e menor em F1 (2,38 mL NaOH N/100 g). O teor de acidez pode indicar falta de higiene no processo e também ser uma característica de processos artesanais, onde o processo é mais lento. Segundo Cereda \& Vilpoux (2003), a acidez na farinha d'água é um fator de qualidade e, neste caso, a legislação não pode ser aplicada. A acidez da farinha permite obter informações sobre o processo de fermentação pela qual passou o produto. Quanto maior a acidez, maior a intensidade da fermentação ou tempo de processo de pubagem das raízes, no caso das farinhas d'água.

Com relação ao pH, as farinhas secas F15 e F7 apresentaram os maiores valores, correspondentes a 6,10 e 5,9, respectivamente, enquanto F13, o menor $\mathrm{pH}$ $(4,24)$. Entre as farinhas d'água, não houve diferença estatística entre F10 e F2, farinhas com menor valor de $\mathrm{pH}$.

A caracterização físico-química da farinha de tapioca encontra-se na Tabela 3. Os resultados obtidos estão todos dentro dos limites especificados pela legislação (umidade- máxima de 14\%; amido- mínimo de 80 g/100 g; cinzas- máximo de 0,5 g/100 g e acidez- máxima de $2 \mathrm{~mL} \mathrm{NaOH} \mathrm{N/100} \mathrm{g)} \mathrm{(BRASIL,} \mathrm{1978).} \mathrm{Com} \mathrm{exceção}$ do teor de fibras, todos os demais componentes analisados estiveram abaixo dos valores médios encontrados por Guimarães et al. (1998), analisando amostras comerciais de farinha de tapioca coletadas em feiras de Belém/PA. Devido à farinha de tapioca ser um produto elaborado a partir da fécula da mandioca, apresentando elevado teor de amido, encontrou-se baixos teores de fibras, proteínas, matéria graxa e açúcares, quando comparados com os obtidos nas farinhas secas e d'água.

Ciênc. agrotec., Lavras, v. 30, n. 4, p. 692-700, jul./ago., 2006 
TABELA 3 - Composição físico-química da farinha de tapioca (F14).

\begin{tabular}{lc}
\hline \multicolumn{1}{c}{ Variáveis $(\mathbf{g} / \mathbf{1 0 0 g})$} & Farinha de Tapioca \\
\hline Umidade & 5,71 \\
Cinzas & 0,10 \\
Fibras & 0,31 \\
Proteínas & 0,02 \\
Matéria graxa & 0,13 \\
Açúcares solúveis totais & 0,10 \\
Amido & 89,92 \\
pH & 4,31 \\
Acidez * & 0,94 \\
\hline
\end{tabular}

* $\mathrm{mL} \mathrm{NaOH} 1 \mathrm{~N} / 100 \mathrm{~g}$ amostra.

\section{Análise granulométrica}

Os resultados referentes à granulometria das farinhas analisadas encontram-se na Tabela 4. Verificouse que somente duas farinhas $(13,33 \%)$ tiveram classificação diferente da requerida pela legislação (F2 MA e F7 - MT). Essas farinhas apresentaram maior quantidade retida (\%) na peneira que a preconizada pela legislação (BRASIL, 1978), conforme sua classificação. No caso de F2, o percentual retido na peneira de abertura de $2,0 \mathrm{~mm}$ foi de $78,55 \%$, superior a quantidade permitida pela legislação (máximo 30,0 \%). A farinha $\mathrm{F} 7$ reteve 3,02 \% na mesma peneira citada anteriormente, enquanto que a legislação determina ausência de retenção nesta peneira, e apresentou 32,86 \% de retenção na peneira de abertura de $0,85 \mathrm{~mm}$, superior ao valor especificado na legislação para este tipo de farinha $(3,0$ a $20,0 \%)$. As farinhas d'água analisadas apresentaram um perfil de partículas bem mais grossas que as farinhas secas, conforme previsto, pois este perfil é proporcionado, entre outros, pela maior temperatura de secagem.

\section{Colorimetria}

Os resultados referentes à colorimetria das farinhas de mandioca analisadas encontram-se na Tabela 5.

A análise dos componentes de cor $\mathrm{L}^{*}, \mathrm{a}^{*}$ e $\mathrm{b}^{*}$ nas diferentes farinhas mostrou variação significativa entre elas, tendo o componente L* (luminosidade ou brilho) variado de 78,43 a 92,8 . As mais escuras foram as farinhas secas/finas de MG (F9) e SP (F5). Esta última passou por um processo complementar de torrefação, podendo-se explicar sua menor luminosidade. As farinhas d'água do MA (F2) e do PA (F10) e a farinha seca do AC (F8), apesar de serem classificadas quanto à cor nas classes amarela e creme, não diferiram significativamente das farinhas brancas para este componente de cor. Verificou-se que as farinhas d'água analisadas apresentaram valores de luminosidade semelhantes aos relatados por Daiuto et al. (2003), citados por Vilpoux (2003).

A coordenada de cromaticidade $\mathrm{a}^{*}$ das farinhas apresentou valores que variaram de $-6,33$ a 4,10 . Considerando que este componente de cor varia de (-60) verde ao $(+60)$ vermelho, ocorreu pequena variação entre as farinhas para este componente. Faz-se importante ressaltar que as farinhas paulistas não diferiram significativamente para este parâmetro, apresentando presença do vermelho. Os valores encontrados para as farinhas d'água diferiram daqueles citados por Daiuto et al. (2003), citados por Vilpoux (2003), pois este autor encontrou predomínio da tonalidade vermelha, enquanto nas farinhas analisadas, houve maior tendência para o verde, porém de pouca intensidade. Destaca-se que as farinhas com menor luminosidade (F9 - amarela, MG e F5 torrada, SP) apresentaram os maiores valores para a tonalidade vermelha, e a farinha mais clara (F8) teve dominante a tonalidade verde.

Já a coordenada de cromaticidade $b^{*}$, que varia de (-60) azul até (+60) amarelo, apresentou uma variação de 6,33 a 38,77, mostrando tendência ao amarelo em todas as farinhas analisadas. Segundo Vilpoux (2003), valores maiores poderiam corresponder a farinhas com corantes artificiais, uma vez que as mandiocas de polpa amarela proporcionam uma cor geralmente menos intensa à farinha. As farinhas secas, fina e grossa, do Pará (F12 e F13) classificadas como amarelas, foram as que apresentaram maiores valores de $b^{*}$, ou seja, alta intensidade do croma amarelo. Entre os consumidores, a cor amarela constitui aspecto desejável para farinha de mandioca d'água. Verificou-se que algumas farinhas de classes diferentes como, por exemplo, F1 e F2 (MA), não diferiram estatisticamente para o valor $b^{*}$. Comparado com a farinha de trigo - valor de croma b* igual a 9,86 segundo Chang \& Flores (2004), notou-se que as farinhas de mandioca analisadas apresentaram valores bem maiores, verificando-se maior presença de croma amarelo nesta última. A farinha de tapioca (F14) apresentou menor valor de $b^{*}$. 


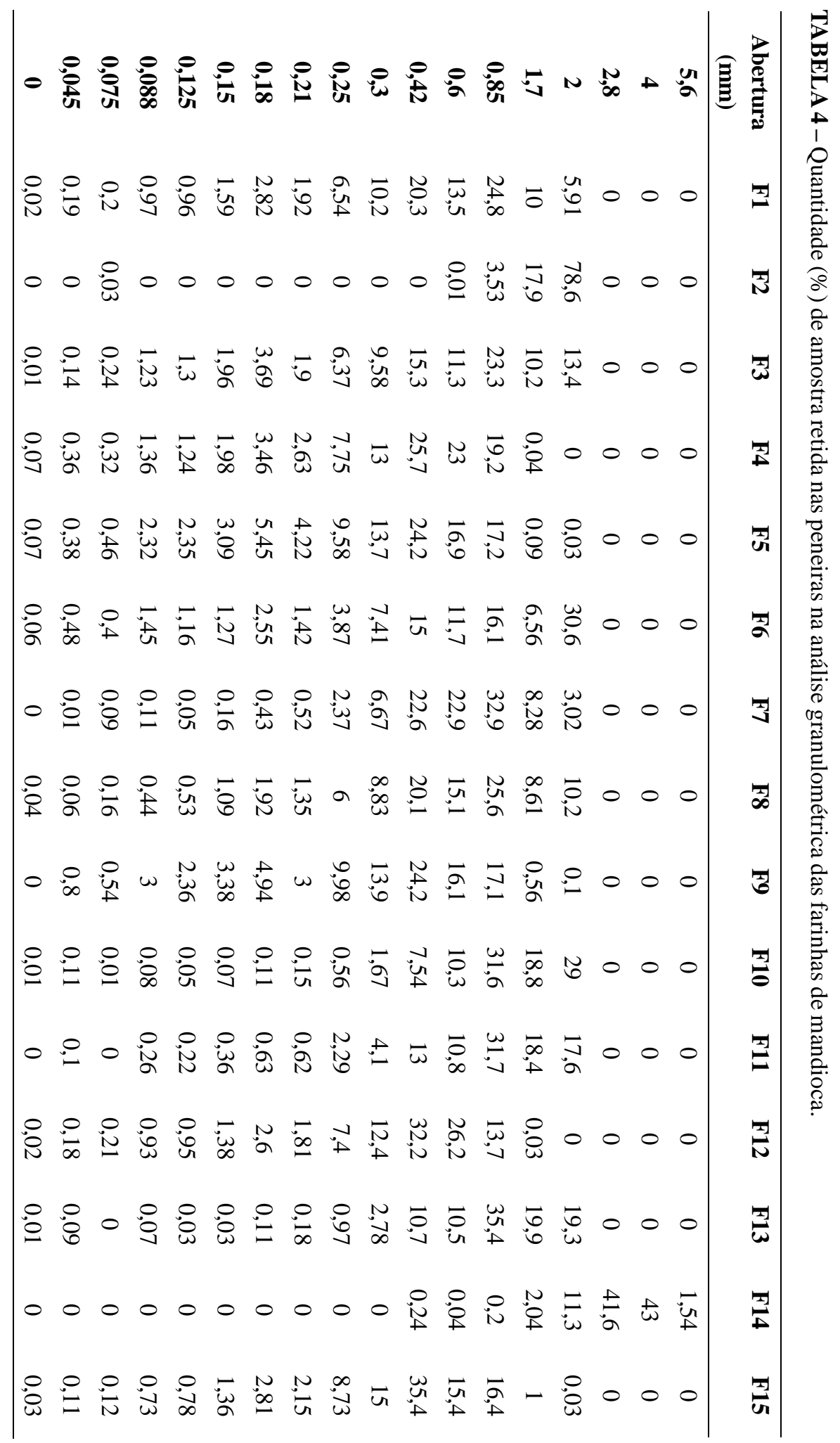


TABELA 5 - Avaliação da cor pelos parâmetros $L^{*}$, a* e b* nas farinhas de mandioca.

\begin{tabular}{cccc}
\hline Farinhas** & $\mathbf{L}^{*}$ & $\mathbf{a}^{*}$ & $\mathbf{b}^{*}$ \\
\hline F1 & $92,8 \mathrm{ab}$ & $-0,63 \mathrm{de}$ & $12,07 \mathrm{fg}$ \\
F2 & $91,63 \mathrm{abc}$ & $-0,23 \mathrm{de}$ & $11,13 \mathrm{~g}$ \\
F3 & $86,9 \mathrm{de}$ & $1,4 \mathrm{bc}$ & $14,10 \mathrm{def}$ \\
$\mathbf{F 4}$ & $86,37 \mathrm{e}$ & $1,47 \mathrm{bc}$ & $14,77 \mathrm{de}$ \\
F5 & $78,43 \mathrm{~g}$ & $3,77 \mathrm{a}$ & $25,97 \mathrm{~b}$ \\
F6 & $84,2 \mathrm{f}$ & $2,27 \mathrm{~b}$ & $18,33 \mathrm{c}$ \\
F7 & $92,7 \mathrm{ab}$ & $-0,63 \mathrm{de}$ & $12,33 \mathrm{efg}$ \\
F8 & $93,0 \mathrm{a}$ & $-2,67 \mathrm{f}$ & $18,16 \mathrm{c}$ \\
F9 & $79,23 \mathrm{~g}$ & $4,10 \mathrm{a}$ & $20,20 \mathrm{c}$ \\
F10 & $91,5 \mathrm{abc}$ & $-0,43 \mathrm{de}$ & $13,57 \mathrm{defg}$ \\
F11 & $92,3 \mathrm{ab}$ & $-0,33 \mathrm{de}$ & $11,9 \mathrm{fg}$ \\
F12 & $88,0 \mathrm{~d}$ & $-4,57 \mathrm{~g}$ & $38,5 \mathrm{a}$ \\
F13 & $90,5 \mathrm{c}$ & $-6,33 \mathrm{~h}$ & $37,8 \mathrm{a}$ \\
F14 & $91,4 \mathrm{bc}$ & $0,50 \mathrm{~cd}$ & $6,33 \mathrm{~h}$ \\
F15 & $91,7 \mathrm{abc}$ & $-1,20 \mathrm{e}$ & $14,9 \mathrm{~d}$ \\
\hline
\end{tabular}

** Médias seguidas de mesma letra na coluna não diferem entre si ao nível de 5\% pelo teste de Tukey.

\section{CONCLUSÕES}

A partir dos resultados obtidos foi possível concluir que:

a) Quanto à composição centesimal, as farinhas de mandioca analisadas diferem entre si, e entre as regiões produtoras, inclusive para classificações de mesmo grupo e subgrupo;

b) Com relação aos teores de umidade, cinzas e amido, todas as farinhas encontram-se dentro dos limites fixados pela legislação, sendo que para proteínas, todas se encontram fora desse limite;

c) As farinhas analisadas apresentam teores baixos a moderados de fibras, contudo, devido ao seu amplo consumo pela população, constituem uma importante opção como fonte de fibras na dieta, além do baixo preço do produto favorecer sua maior utilização; d) Com exceção da farinha de tapioca, os níveis de acidez das farinhas analisadas não estão de acordo com a legislação, demonstrando que características artesanais da produção interferem neste parâmetro;

e) As farinhas analisadas estão de acordo com os critérios da legislação para classificação granulométrica, com exceção de duas farinhas provenientes dos Estados de Mato Grosso e Maranhão, que não se enquadram nesses limites.

f) A classificação de algumas farinhas quanto à cor não está de acordo com as análises de seus componentes de cromaticidade.

\section{REFERÊNCIAS BIBLIOGRÁFICAS}

ASSOCIATION OF OFFICIAL ANALYTICAL CHEMISTS. Official methods of analysis. 13. ed. Washington, 1980. $109 \mathrm{p}$. 
BORBA, A. L. Efeito de alguns parâmetros operacionais nas características físicas, físico-químicas e funcionais de extrusados da farinha de batata-doce (Ipomoea batatas). 2005. Dissertação (Mestrado em Tecnologia de Alimentos) - Escola Superior de Agricultura "Luiz de Queiroz", Universidade de São Paulo, Piracicaba, 2005.

BRASIL. Decreto n ${ }^{\circ}$ 12.486, de 20 de outubro de 1978. Normas técnicas especiais relativas a alimentos e bebidas. Diário Oficial do Estado de São Paulo, São Paulo, p. 20, 21 out. 1978.

CAMPOS, H. Estatística aplicada à experimentação com cana-de-açúcar. Piracicaba: FEALQ, 1984. 297 p.

CEREDA, M. P.; CATÂNEO, A. Avaliação de parâmetros de qualidade da fécula fermentada de mandioca. Revista Brasileira de Mandioca, Cruz das Almas, v. 5, n. 2, p. 5562, 1986.

CEREDA, M. P.; VILPOUX, O. F. Tecnologias, usos e potencialidades de tuberosas amiláceas latino americanas. São Paulo: Fundação Cargill, 2003. v. 3, 711 p.

CEREDA, M. P.; VILPOUX, O. F.; TAKAHASHI, M. Balança hidrostática como forma de avaliação do teor de massa seca e amido. In: CEREDA, M. P.; VILPOUX, O. F. Tecnologias, usos e potencialidades de tuberosas amiláceas latino americanas. São Paulo: Fundação Cargill, 2003. v. 3, p. 30-46.

CHANG, Y. K.; FLORES, H. E. M. Qualidade tecnológica de massas alimentícias frescas elaboradas de semolina de trigo durum (T. Durum 1.) e farinha de trigo (T. Aestivum 1.). Ciência e Tecnologia de Alimentos, Campinas, v. 24, n. 4, out./dez. 2004. Disponível em: 〈hhttp://Www.scielo.br. Acesso em: 2 set. 2005.
FERREIRA NETO, C. J.; FIGUEIREDO, R. M. F.; QUEIROZ, A. J. M. Avaliação físico-química de farinhas de mandioca durante o armazenamento. Revista Brasileira de Produtos Agroindustriais, Campina Grande, v. 5, n. 1, p. 25-31, 2003.

GUIMARÃES, M. C. de et al. Caracterização tecnológica e química do produto farinha de tapioca. In: ENCONTRO DE PROFISSIONAIS DE QUÍMICA DA AMAZÔNIA, 6., 1998, Manaus. Anais... Manaus: Associação dos Profissionais de Química da Amazônia, 1998. p. 179-188.

INSTITUTO ADOLFO LUTZ. Normas analíticas do Instituto Adolfo Lutz: métodos químicos e físicos para análise de alimentos. 2. ed. São Paulo, 1976. v. 1, 371 p.

MATTOS, L. L.; MARTINS, I. S. Consumo de fibras alimentares em população adulta. Revista de Saúde Pública, São Paulo, v. 34, p. 50-55, 2000.

NELSON, N. A. Photometric adaptation of the Somogy method for the determination of glucose. Journal Biology Chemistry, Baltimore, n. 153, p. 375-380, 1944.

SGARBIERI. Problemas brasileiros de alimentação e nutrição. In: Alimentação e Nutrição: fator de saúde e desenvolvimento. São Paulo: Almed, 1987. p. 336343.

SOMOGY, M. Determination of blood sugar. Journal Biology Chemistry, Baltimore, n. 160, p. 69-73, 1945.

VILPOUX, O. Produção de farinha d'água no estado do maranhão. In: CEREDA, M. P.; VILPOUX, O. F. Tecnologias, usos e potencialidades de tuberosas amiláceas latino americanas. São Paulo: Fundação Cargill, 2003. v. 3, p. 621-642. 